\title{
Antioxidant and Antimicrobial Activities of Larrea Divaricata Cav. Aqueous Extract on Vitamin C from Natural Orange Juice
}

\author{
Patricia Micucci $^{1}$, Maria Rosario Alonso ${ }^{1}$, Sebastian Turner ${ }^{1}$, Roberto Davicino ${ }^{1}$, Claudia Anesini ${ }^{1,2}$ \\ ${ }^{1}$ IQUIMEFA-CONICET-UBA, Buenos Aires, Argentina; ${ }^{2}$ Pharmacognosy Unit, Faculty of Pharmacy and Biochemistry, University \\ of Buenos Aires, Buenos Aires, Argentina \\ Email: canesini@yahoo.com.ar
}

Received August $10^{\text {th }}$, 2010; revised October $9^{\text {th }}$, 2010; accepted October $17^{\text {th }}, 2010$

\begin{abstract}
Larrea divaricata Cav. is a South American plant widely distributed in Argentina with reported antioxidant and antimicrobial activities. Vitamin $C$ (Vit $C$ ) the most important water-soluble antioxidant, is degraded upon factors such as oxygen, heat, light, storage time and temperature, during cooking and in presence of microorganisms. The aim of this work was: to study the antioxidant and antimicrobial activity of an aqueous extract of L. divaricata $(E)$ on Vit $C$ prepared in water and on Vit $C$ from natural orange juice, submitted to different store conditions such as temperatures and oxygen. The antioxidant activity was determined by DPPH method and used to obtained the relative Vit $C$ concentration; Vit $C$ decreased its activity and concentration under temperature and air oxygen, but $E$ allowed Vit $C$ to recover its antioxidant activity and prevented Vit $C$ microorganism contamination. These studies were performed in view to establish whether L. divaricata can be used as a supplement on orange juices capable to prevent Vit $C$ decay and microbial growth.
\end{abstract}

Keywords: Vitamin C, Larrea Divaricata Cav., Antioxidant Activity, Antimicrobial Activity

\section{Introduction}

Vitamin C (Vit C) is considered as a most important water-soluble antioxidant. It is an electron donor and therefore a reducing agent, therefore, it has antioxidant properties preventing other compounds from being oxidized. It is known that the physiological and biochemical actions of vitamin $\mathrm{C}$ are due to its antioxidant capacity. However, Vit $\mathrm{C}$ by itself is oxidized during these processes. Beside, Vit $C$ is an essential nutrient for humans. As it can directly scavenge superoxide radical, singlet oxygen, hydrogen peroxide and hydroxyl radical and protects compounds in extracellular and intracellular spaces in most biological systems and participates in numerous metabolic reactions in all animals and plants, therefore, is required for bone formation to scar tissue repair and also for the synthesis of collagen in humans. The major role of Vit $C$ is the prevention of scurvy, this disease leads to the formation of spots on the skin, spongy gums, and bleeding from the mucous membranes [1]. Because of its antioxidant activity, Vit C is widely used as supplement in different form such as tablets, drink mixes, supplemented orange juices and also, as a food additive [2].

The North American Dietary Reference Intake recommends 90 milligrams per day and no more than 2 grams per day (2000 milligrams per day) [3]. It is generally agreed that a balanced diet without supplementation contains enough Vit $C$ to prevent scurvy in an average healthy adult, while those who are pregnant, smoke tobacco, or are under stress require slightly more.

The richest natural sources of Vit $\mathrm{C}$ are fruits and vegetables, several fruit juices are fortified with Vit C, including apple, cranberry and grape juices; it is also present in some cuts of meat, especially liver. Vit C increases quality and technological properties of food as well as nutritional value [4].

Orange juices are a rich source of Vit C [5]. Concentration of Vit $\mathrm{C}$ is a significant indicator of orange juice quality, and it may serve as an indicator that all processes, which ensure a high quality of the product, have been applied in the production processes.

However, Vit $\mathrm{C}$ is an unstable compound and under less desirable conditions it decomposes easily [6]. Degradation of Vit $\mathrm{C}$ proceeds by both aerobic and anaerobic 
pathways [7] and depends upon many factors such as oxygen, heat, light, storage temperature and storage time [8] and also during cooking. Factors that affect the Vit C contents of citrus fruits include, production factors, climate conditions, maturity state and position on the tree, type of fruits (species and variety), type of container, handling and storage $[9,10]$. Other causes include chemical changes from ripening and senescence (aging) processes occurring in the fruit. Both low and high temperatures can also cause decay on Vit C content. In addition, oxygen has shown to be the most destructive ingredient in juice causing Vit $\mathrm{C}$ degradation. [11]. Physical store conditions do not only alter Vit C but also biological conditions, such as the presence of microorganisms. It is known that, the growth of microorganisms, such as bacteria and fungi, conduce to an important spoilage and decay of Vit C. In turn, microorganisms generate free radicals species which are involved in the rapidly oxidative destroy of the vitamin.

So, the loss of Vit C might be a critical factor for the shelf life of some products as citrus juice concentrates [12] since Vit C content of citrus juices undergoes destruction during storage.

By other way, Larrea divaricata Cav. is a South American plant widely distributed in Argentina. In popular medicine it is used for treatment of tumors, inflamematory disease, rheuma and fever. It has been demonstrated that a metanolic extract presented antioxidant activity [13] and that an aqueous extract exerts antimicrobial activity [14] but there are not studies about the antioxidant activity of the aqueous extract and about the antimicrobial and antioxidant activities of the aqueous extract applied to food conservation.

Based on this information, the aim of this work was: 1) to study the antioxidant activity of an aqueous extract of L. divaricata, 2) to determine the capacity of the extract to protect the oxidation of Vit C (from a water solution or from a natural orange juice) by the exposition at different temperatures and air oxygen, studying the variation of the antioxidant activity and 3) to study the antimicrobial activity of the extract upon the natural orange juice. These studies were performed in view to establish whether $L$. divaricata can be used as a supplement on orange juices capable to prevent Vit C decay and microbial growth under stores conditions.

\section{Materials and Methods}

\subsection{Reagents}

Vitamin C L(+)—ascorbic acid (Anedra) was dissolved in water and orange juice. 2, 2-diphenyl-1-picrylhydrazyl $(6 \mathrm{mg})$ were diluted on $30 \mathrm{ml}$ of absolute ethanol, pro- tected from light and freshly prepared. Buffer TRIS. HCl containing $1.2 \mathrm{~g} \% \mathrm{P} / \mathrm{V}$ of TRISMA (SIGMA) and $\mathrm{HCl}$ $0.1 \mathrm{M}$ to reach $\mathrm{pH}$ 7.4. Agar Müeller Hinton (34 g/l) was prepared in distilled water.

\subsection{Natural Orange Juice}

Fresh fruits of Citrus sinensis (orange) were purchased from vegetable stores in Buenos Aires city. These fruits were washed thoroughly with water and the juice was extracted by mechanical pressure. Then filtered to remove pulp and seeds and used immediately for the study.

\subsection{Plant Material}

Leaves of Larrea divaricata Cav. (Zygophyllaceae), identified by employing morphological, anatomical and histochemical techniques, where used during this study. One voucher specimen was deposited at CEFYBO-CONICET and another at the Museum of Pharmacobotany, School of Pharmacy and Biochemistry, University of Buenos Aires. Aqueous extract was prepared from air-dried leaves as follows: $750 \mathrm{mg}$ were infused with $10 \mathrm{ml}$ of sterilized boiling distilled water and heated with stirring for $45 \mathrm{~mm}$ at $56^{\circ} \mathrm{C}$. After maceration at $5^{\circ} \mathrm{C}$ for $72 \mathrm{~h}$ and centrifugation (20 mm at $1500 \mathrm{rpm}$ ), the supernatant was lyophilized [15].

\subsection{Incubation Conditions}

The samples were prepared as follows: L. divaricata extract (E) and vitamin $C$ in water alone or associated; orange juice; orange juice with $L$. divaricata extract; orange juice with vitamin $C$ (for antimicrobial experiments) and orange juice with both $L$. divaricata extract and vitamin C (for antimicrobial experiments). Both vitamin C and $\mathrm{E}$ were added to sample solutions on concentrations of $1 \mathrm{mg} / \mathrm{ml}$. The incubations were performed under different conditions such as temperatures $\left(5,45\right.$ and $\left.100^{\circ} \mathrm{C}\right)$ and air oxygen to mimic stores conditions. For $5^{\circ} \mathrm{C}$ the samples were conserved in glass containers with hermetic close in refrigerator. For $45^{\circ} \mathrm{C}$ or $100^{\circ} \mathrm{C}$ samples were maintained in glass containers with hermetic close in a stove maintained under the selected temperature. When air oxygen was studied, samples were placed in no hermetic close glass containers at room temperature. All the samples were protected from light. Also, the activity was determined under different incubation times 2, 7 and 10 days for $5^{\circ} \mathrm{C}$ and air oxygen and 1,10 and $20 \mathrm{~h}$ for $45^{\circ} \mathrm{C}$ in the case of Vit $\mathrm{C}$ in water or 1, 2, 3 and 4 days of incubation in the case of Juice.

\subsection{Measurement of DPPH Free Radical-scavenging Activity}

The antioxidant activity of the samples was determined 
analyzing the scavenger activity of the free radical diphenylpicrylhydrazyl (DPPH) (Sigma, St Louis, Mo, USA) in accordance with the method described by Wang [16]. The absorbance of DPPH diluted on water was considered as control. The antioxidant capacity to scavenge the DPPH radical was calculated by the following equation: Scavenging effect (\%): [(1. absorbance of sample/ absorbance of control) $\times 100]$. Results were expressed as Mean \pm SEM of three experiments made by triplicate.

\subsection{Determination of the Antioxidant Activity by the Ferric Thiocyanate Method}

The capacity to inhibit lipid peroxidation was determined by the ferric thiocyanate method (FTC) [17]. A volume of $0.8 \mathrm{ml}$ of each concentration of extract or Vit $\mathrm{C}$ was mixed with $0.05 \mathrm{M}$ phosphate buffer $\mathrm{pH} 7$ and $2.5 \%$ linoleic acid in ethanol to obtain $4 \mathrm{ml}$ of solution. The resulting solutions were incubated at $38.5^{\circ} \mathrm{C}$ in a glass flask. Aliquots were removed at regular intervals and $\mathrm{FeCl} 2 /$ ammonium thiocyanate solution was added in order to allow any peroxides resulting from the oxidation of linoleic acid to react, forming a complex that can be detected spectrophotometrically at $500 \mathrm{~nm}$ (Shimatzu UV 2101). This step was repeated every $24 \mathrm{~h}$ until the control (phosphate buffer plus linoleic acid) reached its maximum absorbance value. Therefore, high absorbance values indicated high levels of lino1eic acid oxidation. Phosphate buffer was used as reaction blank. The total antioxidant activity was expressed as the average of three independent determinations carried out by duplicate. The percentage inhibition of lipid peroxidation of linoleic acid was ca1culated applying the following equation: Inhibition of lipid peroxidation $(\%)=100-[(\mathrm{A} s / \mathrm{Ao}) \mathrm{x}$ $100]$, where $A o$ is the absorbance of the control reaction (linoleic acid alone, $100 \%$ peroxidation) and As is the absorbance obtained in the presence of the sample extract or positive control of antioxidant activity $(1 \mathrm{mg} / \mathrm{ml}$ ascorbic acid).

\subsection{Determination of Relative Vit C Concentration}

In all samples, DPPH free radical-scavenging activity, was used to calculate the relative Vit $\mathrm{C}$ concentration. The relative Vit $\mathrm{C}$ concentration was determined by interpolating the data of antioxidant activity in the graphic DPPH free radical-scavenger activity versus Standard Vit C concentration. Results were expressed as Mean \pm SEM of three experiments made by triplicate.

\subsection{Antimicrobial Activity}

Antimicrobial activity was determined by agar diffusion method. First, dishes with Agar Müeller Hinton were prepared. Then the samples submitted to different store conditions as temperature $45^{\circ} \mathrm{C}$ and $5^{\circ} \mathrm{C}$ and air oxygen during $24 \mathrm{~h}$, were inoculated onto the dish under sterile conditions [18]. The inoculated plates were incubated for $48 \mathrm{~h}$ at $37^{\circ} \mathrm{C}$ for bacterial strains before colony were count, when it was difficult to do a direct county of the microorganism the area was determined [19].

\subsection{HPLC}

The amount of NDGA present in the aqueous extract of $L$. divaricata leaves was determined by HPLC using a Varian chromatograph equipped with a Rheodyne injection valve $(20 \mu \mathrm{l})$. Lyophilized aqueous extracts of three different concentrations (2.5, 7.5 and $22.5 \% \mathrm{p} / \mathrm{v})$ and pure NDGA were dissolved in methanol and analyzed on an ODS column $(250 \mathrm{~mm} \times 4.6 \mathrm{~mm} \mathrm{SYM})$. Compounds were eluted using a gradient from $70 \%$ of a $2 \%$ acetic acid solution (solvent $\mathrm{A}$ ) and $30 \%$ methanol: acetic acid: 98:2 (solvent $\mathrm{B}$ ) to $0 \%$ of $\mathrm{A}$ in 30 minutes at a flow rate of $1 \mathrm{ml} / \mathrm{min}$. NDGA was detected using a UV detector $(280 \mathrm{~nm})$ and a photodiode array detector. For peak purity and identification, NDGA and aqueous extract residues were dissolved in methanol instead of water to minimize oxidation. A calibration curve of NDGA was obtained by injection of $20 \mu \mathrm{l}$ samples of a series of solutions prepared diluting a stock solution of $0.55 \mathrm{mg} / \mathrm{ml}$, starting at $0.02 \mathrm{mg} / \mathrm{ml}$. The quantity of NDGA in the extracts was calculated by interpolation of the peak area in the calibration curve [20].

\subsection{Statistical Analysis}

Student's " $t$ " test for unpaired values was used to determine the levels of significance. When multiple comparesons were necessary, the Dunnett's test was applied after ANOVA. Differences between means were considered significant if $P<0.05$.

\section{Results}

\subsection{Antioxidant Activity}

In order to determine if $L$. divaricata aqueous extract (E) possessed antioxidant activity capable to protect Vit C from oxidation induced by air oxygen and temperatures, firstly, the antioxidant activity of the aqueous extract was studied with two different methods: DPPH scavenger activity and inhibition of lipid peroxidation and was compared with the antioxidant activities exerted by a Vit $\mathrm{C}$ used as control; moreover, these studies allowed to select the optimal antioxidant concentration to be used in the following experiments.

In Figure 1, it can be seen that, the extract exerted anioxidant activity by the two methods in a response concentration relationship, the maximum activity was ob- 
served with $1000 \mu \mathrm{g} / \mathrm{ml}$ (Figures 1(a) and (b)); by other way, vitamin $\mathrm{C}$ also exerted antioxidant activity in relation to concentrations, in this case, also, the maximum activity was obtained with $1000 \mu \mathrm{g} / \mathrm{ml}$ (Figure 1(c) and (d)). As E presented a maximum effect at $1000 \mu \mathrm{g} / \mathrm{ml}$, this concentration was selected for the association of $\mathrm{E}$ and Vit $\mathrm{C}$ in the following experiments. The concentration of Vit $\mathrm{C}$ for association with $\mathrm{E}$ was selected taking into account the concentration of Vit $\mathrm{C}$ used for juice supple-mentation $(1000 \mu \mathrm{g} / \mathrm{ml})$.

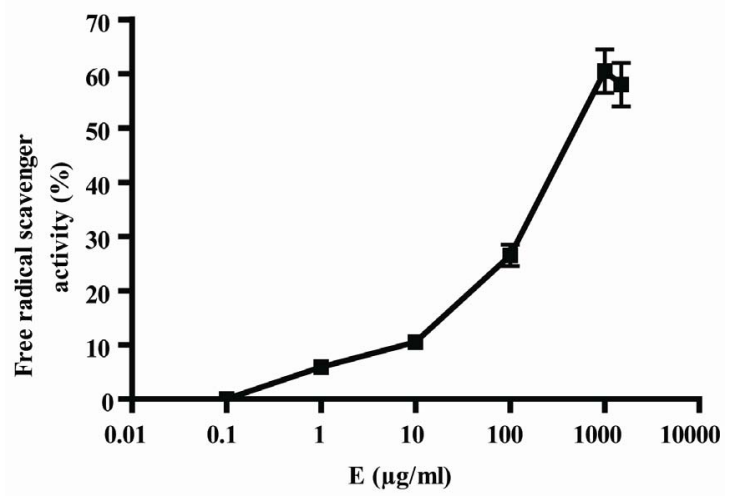

(a)

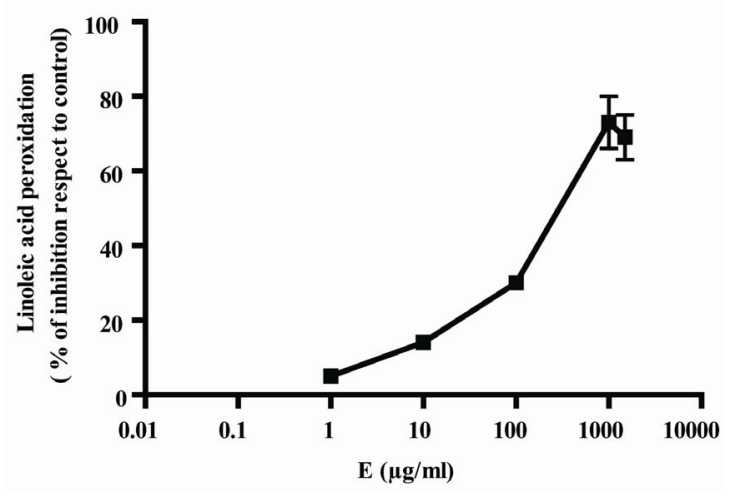

(b)

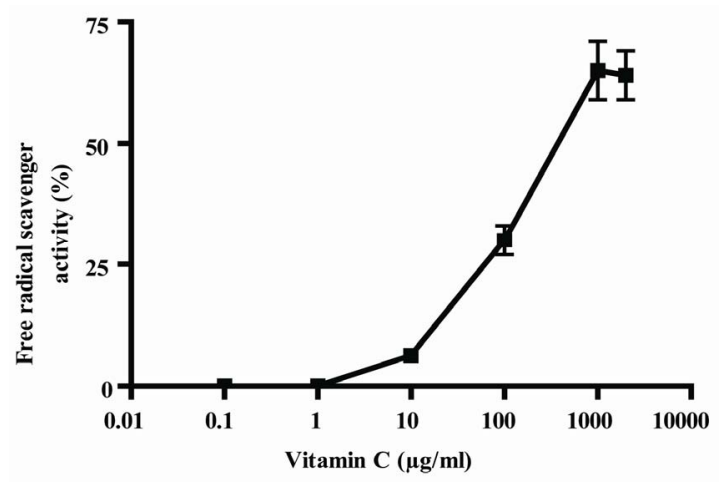

(c)

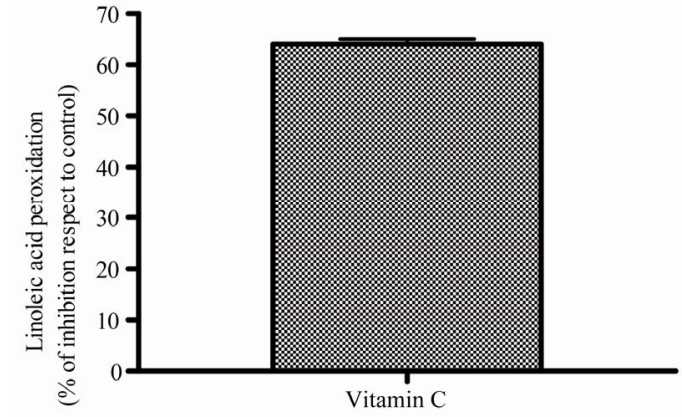

(d)

Figure 1. Antioxidant activity of extract (E) and Vit C. Free radical scavenger activity of extract $(E)(a)$ and vitamin $C$ (Vit C) (c); inhibition of linoleic acid peroxidation of extract (b) and Vit $C$ (d). The extract and Vit $C$ were analyzed in different concentrations (from 0.01 to $1500 \mu \mathrm{g} / \mathrm{ml}$ ). Results represent Mean \pm SEM of three experiments performed by triplicate.

Secondly, the protective effect of $\mathrm{E}$ on Vit C dissolved in water, under different temperatures and air oxygen, mimicking different stores conditions, was studied. The effect of different temperatures on Vit $\mathrm{C}$ as well as the protection exerted by $\mathrm{E}$ on Vit $\mathrm{C}$, were investigated through out the variation in free radical scavenger activity and the relative concentration of Vit $\mathrm{C}$ was calculated using these values which were interpolated in Figure 1(c). To do this, the antioxidant activity of Vit $C$ was determined incubating it alone or in presence of $\mathrm{E}$ during $1 \mathrm{~h}$ at different temperatures $\left(5,45\right.$ and $\left.100^{\circ} \mathrm{C}\right)$, these conditions were selected taking into account manufacturing, conservation and environmental conditions at which natural juices are usually exposed to. In Figures 2 (a) and (b), it can be seen that, relative Vit C concentration decreased significantly at both low and high temperatures. The major loss was at 45 and $100^{\circ} \mathrm{C}$, but no significantly differences were observed between them. When both antioxidants were incubated together, the loss of Vit C was lower (Figures 2(a) and (b)).

As there were no significantly differences between 45 and $100^{\circ} \mathrm{C}$, then $5^{\circ} \mathrm{C}$ and $45^{\circ} \mathrm{C}$ were chosen as temperatures for posterior studies. Under this condition, samples were incubated during different times. At $5^{\circ} \mathrm{C}$, Vit $\mathrm{C}$ decreased its activity and the relative concentration from 2 to 10 days of incubation. The major decrease or loss was observed at 7 and 10 days of incubation (Figures 2(c) and (d)). When both $\mathrm{E}$ and Vit $\mathrm{C}$ were incubated together, Vit $\mathrm{C}$ increased its activity at the same time that increased its relative concentration, showing a minor loss ( Figures 2(c) and (d)).

Besides, at $45^{\circ} \mathrm{C}$, the incubations were done until $20 \mathrm{~h}$, if the incubation was prolonged in the time a great con- 
tamination was observed. Under these conditions Vit C decreased also its activity and relative concentrations, no differences were observed at different times (Figures 2(e) and (f)). Again, when Vit $\mathrm{C}$ and $\mathrm{E}$ were incubated together, Vit $\mathrm{C}$ presented more activity and higher relative concentration that when was incubated alone (Figure 2(e) and (f)).

The effect of air oxygen on Vit C's antioxidant activity and relative concentration was also studied. The samples were incubated during different times, until 10 days of incubation. Vit C decreased its activity and relative concentration, the loss was major at prolonged times ( 7 and 10 days) (Figures 2 (g) and (h)). When $\mathrm{E}$ and Vit $\mathrm{C}$ were incubated together, the antioxidant activity and relative concentration of Vit $\mathrm{C}$ were higher than when was incubated alone (Figures 2(g) and (h)). E increased Vit C antioxidant activity and relative concentration, showing an absence of Vit C loss (Figures 2(g) and (h)).

Third, the same experiments were performed in Vit C from an orange juice (J). So, it was analyzed the capacity of $\mathrm{E}$ to protect Vit $\mathrm{C}$ of $\mathrm{J}$, from temperature and air oxygen; the temperatures and time of incubation were selected from the experiments performed before.

At $5^{\circ} \mathrm{C}$, $\mathrm{J}$ decreased significantly its antioxidant activeity and relative Vit $\mathrm{C}$ concentration at 2, 3 and 4 days of incubation, the loss was major at prolonged times (Figures 3(a) and (b)), the association with $E$ increased significantly $\mathrm{J}$ activity and relative Vit $\mathrm{C}$ concentration, a great decrease in Vit C loss was observed (Figures 3(a) and (b)).

At $45^{\circ} \mathrm{C}$, the juice $(\mathrm{J})$ decreased its antioxidant activity and also the relative Vit $\mathrm{C}$ concentration, depending on the time incubation (1, 2, 3, and 4 days of incubation), the major decreased or loss was observed at high incubation times (Figures 3(c) and (d)); in presence of E, J recovered significantly its activity and relative Vit $\mathrm{C}$ concentration, showing a significantly decrease in loss at 1 and 2 days of incubation.

The air oxygen decreased significantly the antioxidant activity and concentrations of $\mathrm{J}$ in relation to incubation days (Figures 3(e) and (f)). When $\mathrm{E}$ was added to $\mathrm{J}$, an increase of the Vit $\mathrm{C}$ relative concentration was observed (Figures 3(e) and (f)).

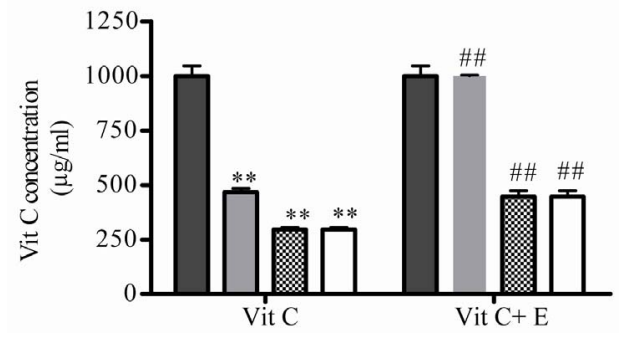

(a)

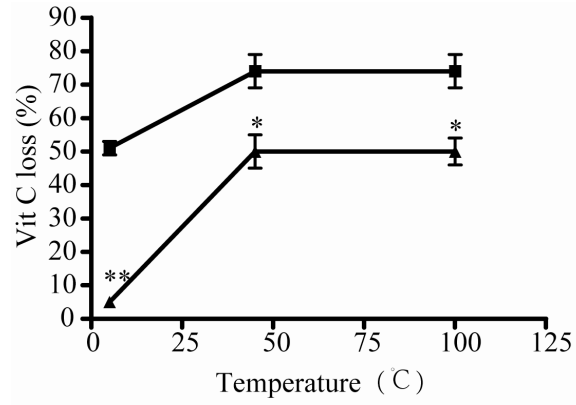

(b)

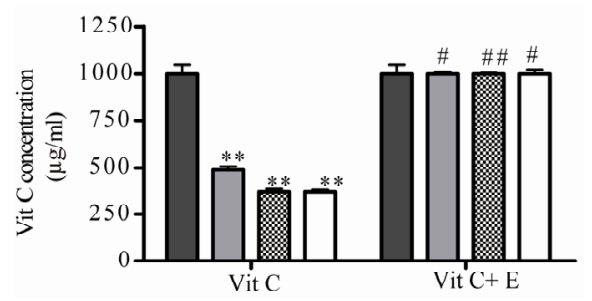

(c)

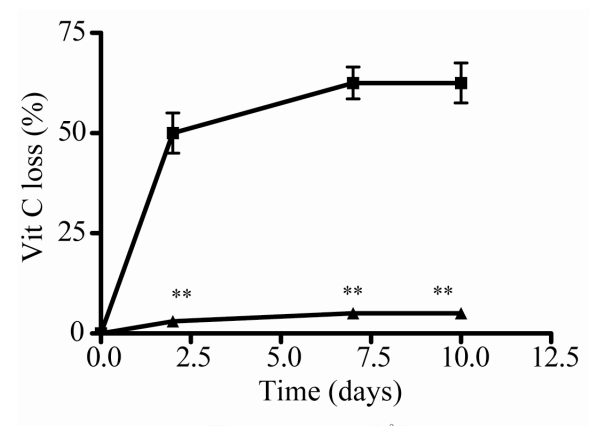

Temperature $5{ }^{\circ} \mathrm{C}$

(d)

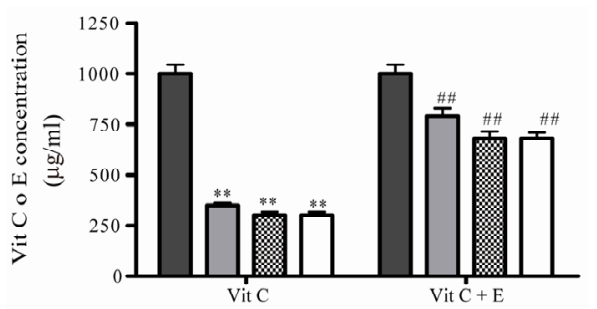

(e)

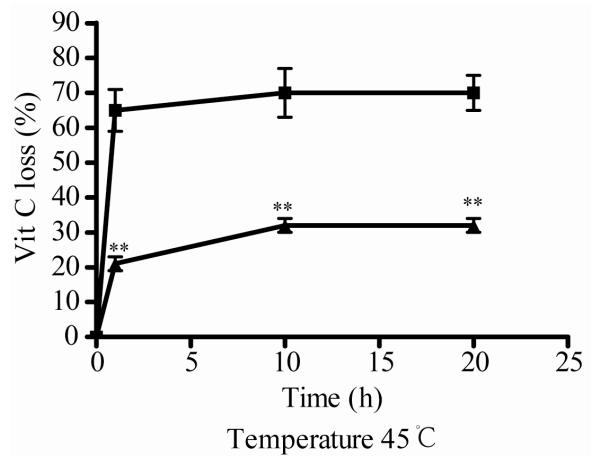

(f) 


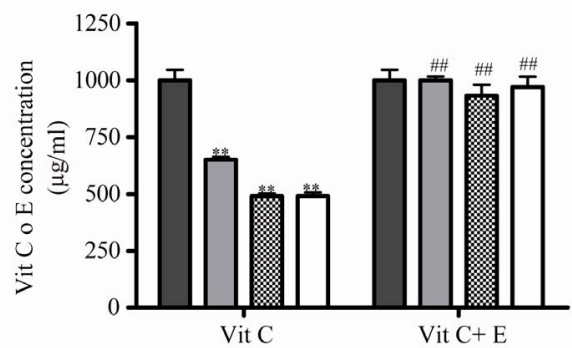

(g)

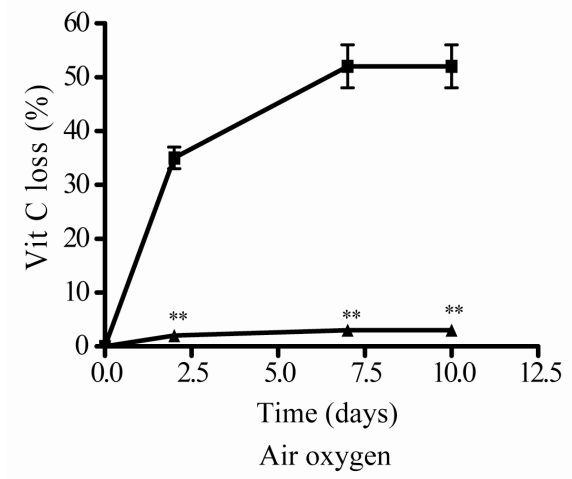

(h)

Figure 2. Effect of $\mathbf{E}$ on relative Vit $\mathrm{C}$ concentration. (a) Vit $\mathrm{C}$ relative concentration and (b) $\mathrm{Vit} \mathrm{C}$ loss under different temperatures 5,45 and $100^{\circ} \mathrm{C}$ during $1 \mathrm{~h}$. (c) Vit $\mathrm{C}$ relative concentration and (d) $\mathrm{Vit} \mathrm{C}$ loss under $5^{\circ} \mathrm{C}$ during different times (2, 7 and 10 days). (e) Vit $\mathrm{C}$ relative concentration and (f) Vit $\mathrm{C}$ loss under $45^{\circ} \mathrm{C}$ during different times (1, 10 and 20 h). (g) Vit $C$ relative concentration and (h) Vit $C$ loss under air oxygen during different times (2, 7 and 10 days). In Figures (b), (d), (f) and (h) loss of $\mathrm{Vit} C$ in absence of $\mathrm{E}$ (a), loss of Vit $\mathbf{C}$ in presence of $\mathbf{E}(\Delta) . * * \mathbf{p}<0.01, * \mathbf{p}<0.05$ significantly differences between loss of Vit $C$ in absence and presence of $E$, in accordance to Student's $T$ test. (a) Black column: Activity or concentration determined immediately after sample preparation (day 0); grey column: Activity or concentration determined at $5^{\circ} \mathrm{C}$ after $1 \mathrm{~h}$ of incubation; column with points: activity or concentration determined at $45^{\circ} \mathrm{C}$ after $1 \mathrm{~h}$ of incubation and white column: activity or concentration determined at $100^{\circ} \mathrm{C}$ after $1 \mathrm{~h}$ of incubation. (c), (e) and (g): Black column: Activity or concentration determined immediately after sample preparation (day 0); grey column: Activity or concentration determined at $5^{\circ} \mathrm{C}$ or $45^{\circ} \mathrm{C}$ after 2 days or $1 \mathrm{~h}$ of incubation; column with points: Activity or concentration determined at $5^{\circ} \mathrm{C}$ or $45^{\circ} \mathrm{C}$ after 7 days or $10 \mathrm{~h}$ of incubation and white column: Activity or concentration determined at $5^{\circ} \mathrm{C}$ or $45^{\circ} \mathrm{C}$ after 10 days or $20 \mathrm{~h}$ of incubation. Results represent the Mean \pm SEM of three determinations made by triplicate. $\# p<0.05, \# \# \mathbf{p}<0.01$ significantly differences between Vit $\mathbf{C}$ alone and Vit $\mathbf{C}+\mathrm{E}$, in accord with ANOVA + Dunnett's test. * $p<0.05, * * p<0.01$ significantly differences between Vit $\mathrm{C}$ immediately prepared and Vit $\mathrm{C}$ submitted to different temperatures or different incubation times in accord with ANOVA + Dunnett's test.

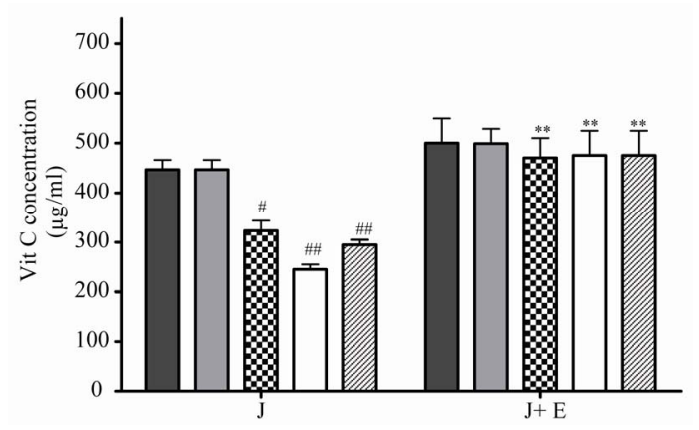

(a)

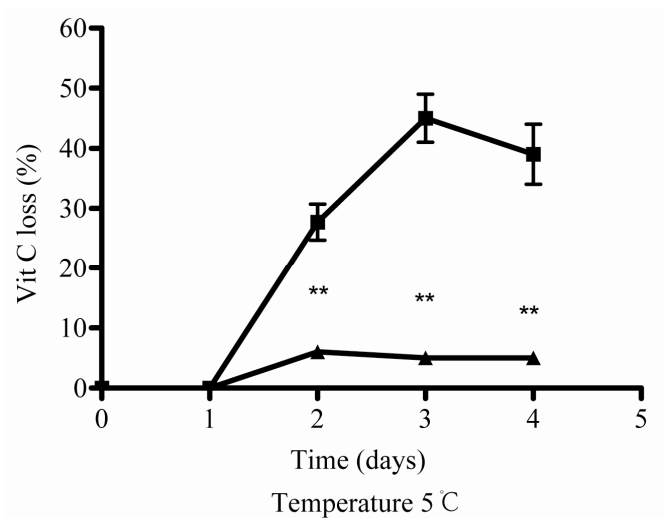

(b)

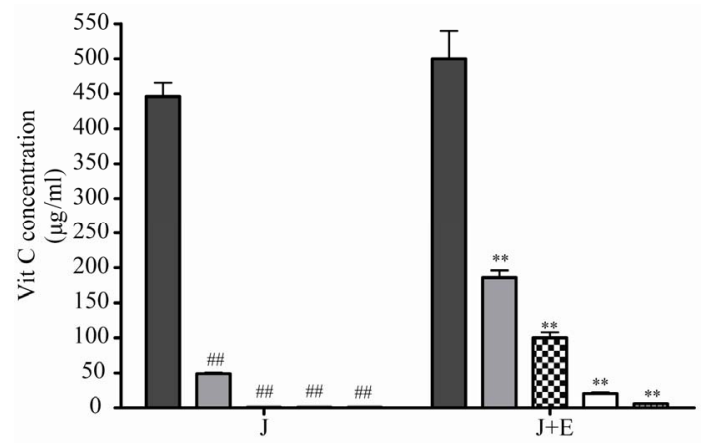

(c)

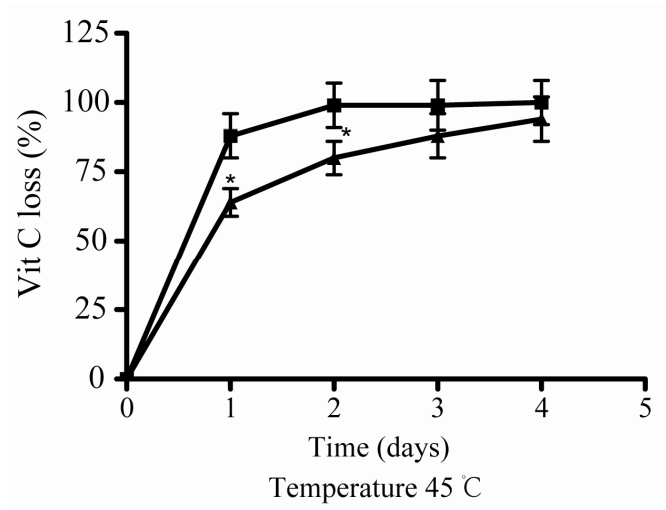

(d) 


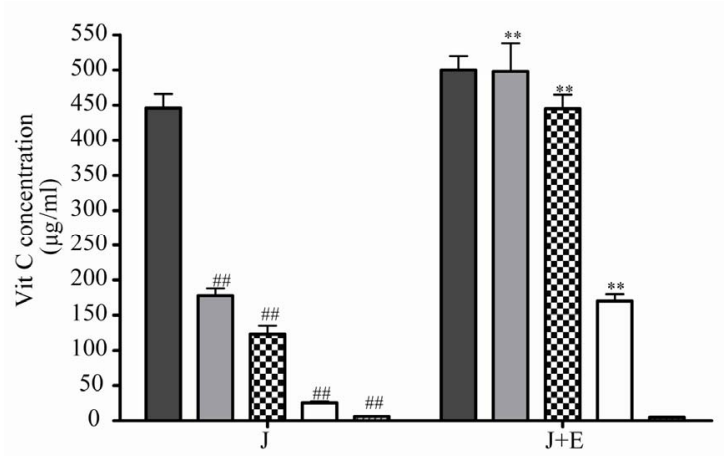

(e)

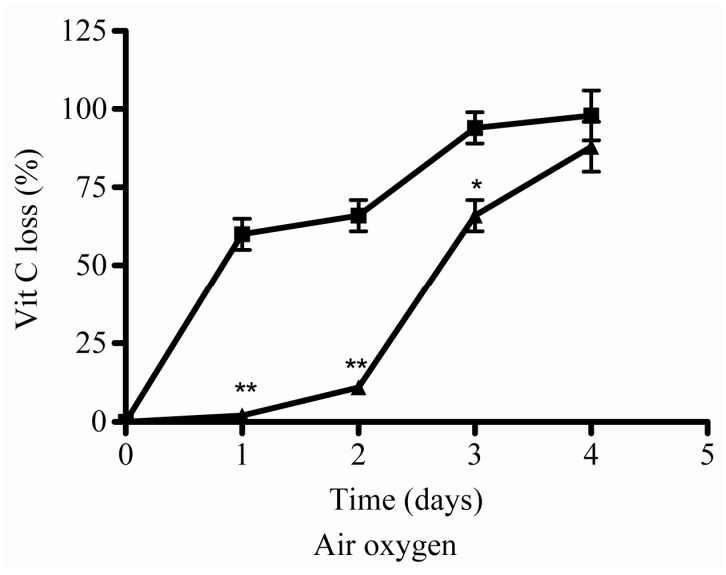

(f)

Figure 3. Effect of $\mathbf{E}$ on Vit $\mathrm{C}$ of natural juice (J) submitted to different conditions. (a) Vit $\mathrm{C}$ relative concentration and (b) Vit $\mathrm{C}$ loss under $5^{\circ} \mathrm{C}$ during different times $(1,2,3$ and 4 days). (c) Vit $\mathrm{C}$ relative concentration and (d) Vit $\mathrm{C}$ loss under $45^{\circ} \mathrm{C}$ during different times (1, 2, 3 and 4 days). (e) Vit $C$ relative concentration and (f) Vit $C$ loss under air oxygen during different times (1, 2, 3 and 4 days). In Figures (b), (d), (f): loss of Vit $\mathrm{C}$ in absence of $\mathrm{E}(\boldsymbol{\square})$, loss of Vit $\mathrm{C}$ in presence of $\mathbf{E}(\Delta) .{ }^{* *} \mathbf{p}<0.01, * \mathbf{p}<0.05$ significantly differences between loss of $\mathrm{Vit} C$ in absence and presence of $E$, in accordance to Student's $T$ test. Black column: Activity or concentrations of sample immediately prepared, grey column: Activity or concentration at 1 day of incubation, column with squares: Activity or concentration at 2 days of incubation, white column: Activity or concentration at 3 days of incubation and column with lines: Activity or concentration at 4 days of incubation. Results represent the Mean \pm SEM of three determinations made by triplicate. *p $<0.05, * * p<0.01$ significantly differences between Vit $\mathbf{J}$ alone and $\mathbf{J}+\mathbf{E}$, in accord with ANOVA + Dunnett's test. $\# \mathbf{p}<0.05, \# \# \mathbf{p}<0.01$ significantly differences between $\mathbf{J}$ immediately prepared and $J$ submitted to different temperatures in accord with ANOVA + Dunnett's test.

\subsection{Antimicrobial Activity}

The antimicrobial activity of $\mathrm{E}$ was determined on oran- ge juice with or without Vit C supplementation and submitted to different conditions as different temperatures $\left(5^{\circ} \mathrm{C}\right.$ and $45^{\circ} \mathrm{C}$ ) and to air. As it can be seen in Figures 4 (a), (b) and (c) and Tables inserted), E diminished microorganism contamination under the three conditions as it was shown by a decrease in culture area.

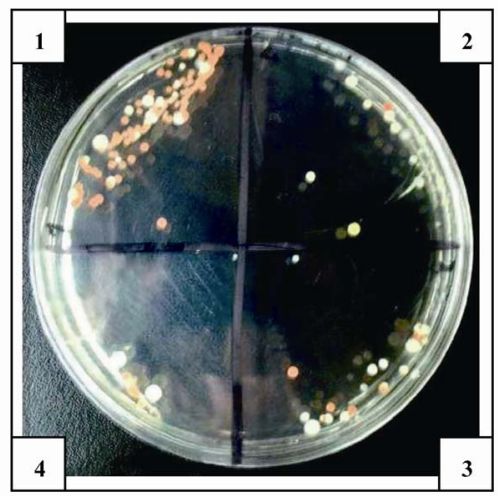

\begin{tabular}{cc}
\hline $\begin{array}{c}\text { Treatments } \\
\text { (Submitted to air) }\end{array}$ & $\begin{array}{c}\text { Area }\left(\mathrm{cm}^{2}\right) \\
(\text { Mean } \pm \text { SEM) }\end{array}$ \\
\hline Juice (1) & $392.76 \pm 91$ \\
Juice + E (2) & $160 \pm 20$ \\
Juice + Vit C (3) & $441 \pm 65$ \\
Juice + Vit C+ E (4) & $66.8 \pm 20$ \\
\hline
\end{tabular}

(a)

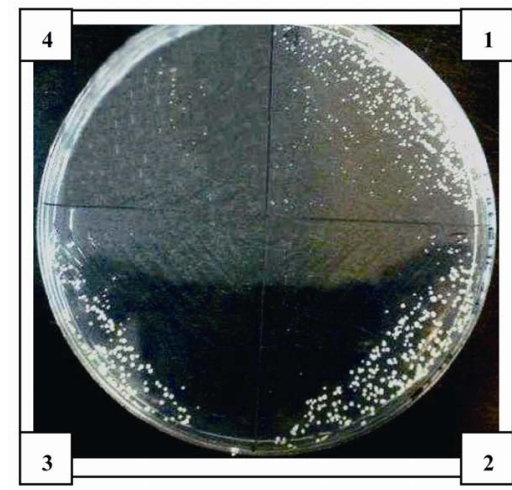

\begin{tabular}{cc}
\hline $\begin{array}{c}\text { Treatments } \\
\left(\text { Submitted to } 5^{\circ} \mathrm{C}\right)\end{array}$ & $\begin{array}{c}\text { Area }\left(\mathrm{cm}^{2}\right) \\
(\text { Mean } \pm \text { SEM })\end{array}$ \\
\hline Juice (1) & $500 \pm 50$ \\
Juice + E (2) & $320.7 \pm 40$ \\
Juice + Vit C (3) & $535.4 \pm 65$ \\
Juice + Vit C+ E (4) & $86.6 \pm 20$ \\
\hline
\end{tabular}

(b) 


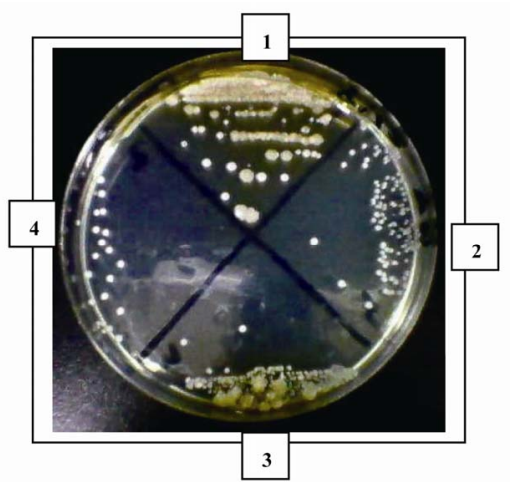

\begin{tabular}{cc}
\hline $\begin{array}{c}\text { Treatments } \\
\left.\text { (submitted to } 45^{\circ} \mathrm{C}\right)\end{array}$ & $\begin{array}{c}\text { Area }\left(\mathrm{cm}^{2}\right) \\
(\text { Mean } \pm \text { SEM) }\end{array}$ \\
\hline Juice (1) & $555 \pm 50$ \\
Juice + E (2) & $415 \pm 30$ \\
Juice + Vit C (3) & $262.8 \pm 30$ \\
Juice + Vit C+ E (4) & $128 \pm 15$ \\
\hline
\end{tabular}

(c)

Figure 4. Antimicrobial activity of $\mathbf{E}$ on Juice (alone or supplemented with Vit $C$ ). The samples were incubated during $48 \mathrm{~h}$ after to be submitted to different store conditions as temperature $45^{\circ} \mathrm{C}$ and $5^{\circ} \mathrm{C}$ and air oxygen during $24 \mathrm{~h}$. The area of microorganism growth were determined scanning the Petri plates as it was described in materials and methods. The photographs are representative from different treatments: (a) submitted to air oxygen; (b) submitted to $5^{\circ} \mathrm{C}$; (c) submitted to $45^{\circ} \mathrm{C}$. The results represent the Mean \pm SEM of three determinations performed by triplicate.

\section{Discussion}

In this work the capacity of an aqueous extract of $L$. divaricata to protect the oxidation of Vit C prepared in water and Vit C from an orange natural juice, was determined under different conditions, such as temperatures and air oxygen. These conditions were chosen to mimic the store conditions, principally $5^{\circ} \mathrm{C}$ (temperature of refrigerator), $45^{\circ} \mathrm{C}$ (tropical temperatures) and $100^{\circ} \mathrm{C}$ was used mimicking food cooking temperature or thermal pasteurisation.

L. divaricata extract possess DPPH scavenger activity in relation to concentrations (Figures 1(a), (b). The extract presented antioxidant activity comparable to Vit C (Figures 1(c) and (d)) as no significantly differences were found between both maximum antioxidant effects. It was shown before that the extract possess antioxidant activity especially inducing peroxidase secretion in submandibulary glands [21]. Similarly, the antioxidant activity of a $L$. divaricata methanolic extract was reported by Pedernera et al [13] who detected antioxidant activity, principally DPPH scavenging activity. The antioxidant action of Vit $\mathrm{C}$ is well known, it is an electron donor and therefore a reducing agent. The curve: DPPH free radical scavenger activity versus Vit $C$ concentration was used to determine Vit $\mathrm{C}$ relative concentration by the interpolation of DPPH scavenger activity obtained at different conditions. Various methods have been reported in the literature for the quantitative determination of Vit C. Some authors, determined Vit $\mathrm{C}$ indirectly by the capacity of Vit C to reduce tetrazolium salt (MTT to formazan) [22].

As may researcher have pointed out that temperature and air oxygen have significant effect on Vit $\mathrm{C}$ destructtion, Vit $\mathrm{C}$ from aqueous solution and $\mathrm{Vit} \mathrm{C}$ from orange juice was submitted to low temperature $5^{\circ} \mathrm{C}$ to $45^{\circ} \mathrm{C}$ and to $100^{\circ} \mathrm{C}$.

As well as Vit $\mathrm{C}$ was affected at low and high temperature, it was more affected by high temperature. The effect of high temperature was observed at short time of incubation, if incubation continuous in time (data no shown) a loss of $100 \%$ of Vit $C$ was observed at the same time that a great contamination occurred. The oxygen also affected Vit C concentration depending on incubation time, the same was observed with low temperature. Nevertheless, no significant differences were shown between 7 and 10 days of incubation, it appeared that loss reached a plateau. Because of this the incubation time was not prolonged.

It was observed that, Vit $\mathrm{C}$ is the compound most afected by temperature and time of storage. Increase of temperature by each $10^{\circ} \mathrm{C}$ caused a distinct decrease in its, also after 6 months of storage at 18,28 and $38^{\circ} \mathrm{C}$ the content of vitamin C decreased by $21 \%, 31 \%$ and $81 \%$, respectively [23]. Furthermore, Kabasakalis et al. [5,24] reported a decrease in Vit $\mathrm{C}$ content in commercial orange juices after 6 months of storage at room temperature by $29 \%$. It is known that, Oxidation of Vit C occurs mainly during the processing of citrus juices, whereas, anaerobic degradation of Vit $\mathrm{C}$ mainly appears during storage and is principally observed in thermally preserved citrus juices $[7,25]$. It was reported that several decomposition reactive products occur via the degradation of vitamin C [26] and these compounds may combine with amino acids, thus result in formation of brown pigments [4].

When $\mathrm{E}$ is added to Vit $\mathrm{C}$, Vit $\mathrm{C}$ recovered its antioxidant activity as well as its relative concentration increased. A minor loss of Vit $C$ in presence of $E$ was observed with air oxygen and low temperature, meanwhile when Vit $C$ was submitted to high temperatures, E could revert partially the degradation induced by temperature.

Vit $C$ from juice was more affected by high tempera- 
ture $\left(45^{\circ} \mathrm{C}\right)$ and air oxygen in relation to incubation time. The incubation was not prolonged in time because a $100 \%$ of degradation was observed with air oxygen and high temperature at 4 days of incubation. At low temperature, Vit $\mathrm{C}$ from juice was also affected but in a minor grade (loss of about 50\%) in comparison when was submitted to air oxygen and high temperature. Under the last conditions, the maximum loss of Vit $\mathrm{C}$ was reached at 3 days of incubation. When $\mathrm{E}$ was added to J, a completely protection was observed at low temperature. At $45^{\circ} \mathrm{C}$ the protection was significantly but minor during 2 days of incubation. With air oxygen the protection was observed at 1, 2 and 3 days of incubation, being completely at 1 and 2 days.

According to the literature data, the content of vit $C$ in different juices decreases during storage, depending on storage conditions, such as temperature, oxygen and light access [24,27]. Loss of added vit $C$ during sterilization of commercial evaporated milk of about $20-30 \%$ has been observed before, also a decrease in vit $\mathrm{C}$ concentration was observed when milk was stored at 21 and $36^{\circ} \mathrm{C}$ [28].

In conclusion, in the model used in this work, Vit C appeared to be affected by high temperature, air oxygen and low temperature. The deleterious effect of high temperature on Vit C concentration was higher than the others conditions. E protected more from low temperature and air oxygen and in a minor grade from high temperature. The fact that E protected more in presence of oxygen is related to its antioxidant activity, as under this condition only oxidative status occurs. At low temperature, Vit C should not be decrease its concentration and activity, it could be possible that something of oxygen in the container could contribute to a oxidative process, so again in presence of oxidative phenomenon, E exerted it antioxidant action. By other way, at high temperature others mechanisms are involved in Vit C destruction different from oxidation [29], because of this, the protective effect of E was lower. Nevertheless E could exert some protective effect perhaps related to the presence of oxygen present in the container.

The antioxidant activity of $\mathrm{E}$ could be related to the presence of NDGA and also to the presence of flavonoids. The presence of NDGA was confirmed by HPLC and represented $0.119 \pm 0.018 \mathrm{~g} \%$ of the dried weight of plant. NDGA was identified by the retention time and UV spectral analysis of the peak against a standard of NDGA (retention time: 19.149 min similar to pure NDGA standard).The aqueous extract presented a concentration of $0.43 \mathrm{~g} / 100 \mathrm{~g}$ of dried residuum, a similar amount was reported before [15]. Previously it was shown that, the resin that covers the leaves contain principally phenolic compounds (flavonoids and NDGA) and essential oils (limonene, camphene, borneol and alcanfor [30]. The presence of saponins and leucoantocianidines was also reported [31]. Among the flavonoids, O-glycosides of quercetin, myricetin and a C-glycoside of apigenin were found [32].

It is reported that, flavonoids exert antioxidant action, attributed to metal chelation, scavenging of radicals, enzyme inhibition, and/or induction of the expression of protective enzymes in biological samples [33]. In addition, there is plenty evidence of the antioxidant activity of NDGA. The free radical scavenging activity of NDGA has been previously reported [34] and prove to possess antioxidant and inhibitory activity on inflammation mediators [35]. Also, has been used as an antioxidant preservative for fats and butter but it is no longer used for this purpose because of its toxicity [36]. But, the antioxidant activity of the extract can be attributed only partly to NDGA as the aqueous extract could be considered an extract with low concentration of NDGA; NDGA is soluble in ethanol, slightly soluble in hot water and insoluble in cold water [37], so these properties reduce significantly the amount of NDGA in the aqueous extracts compared with alcoholic extracts [38]. It is important to note that, the NDGA present in $1000 \mu \mathrm{g} / \mathrm{ml}$ of $L$. divaricata aqueous extract (added to Vit $\mathrm{C}$ or judge for antioxidant activity) is between 3-4 $\mu \mathrm{g} / \mathrm{ml}$. NDGA is a polyphenol compounds that was used before, for its antioxidant activity, in the conservation of fats and butter, in high concentrations, which are related to hepatotoxicity. The concentrations of NDGA related to hepatotoxicity are in order to $50-100 \mu \mathrm{M}(15-30 \mu \mathrm{g} / \mathrm{ml})$ or more [39, 40]. In contrast, low concentrations of NDGA are related to beneficial properties which are of potential use for humans such as, enzyme inhibitor, antimicrobial activity properties, a protector from neurotoxicity and bladder toxicity [41], anticancer and antimutagenic action [42]. Furthermore, it was shown that low concentrations between 1-10 $\mu \mathrm{M}(0.3-6 \mu \mathrm{g} / \mathrm{ml})$ possesses antimitogenic effect in mammalian hepatocytes "in vitro" and "in vivo" [43] also, these concentrations protect against norgentrel induced genotoxic damage in lymphocytes [44]. So, it is important to note that the NDGA content in aqueous extract of the plant is in the order that possesses beneficial effects.

The extract exerted antimicrobial activity, this activity could contribute to prevent the chemical degradation of vit $C$. The antimicrobial activity of $L$. divaricata was previously reported by Pérez and Anesini [45] and Anesini and Pérez [14]. In addition, it is reported that, an aqueous extract from $L$. divaricata inhibits the growth of Helicobacter pylori; considering the low amount of NDGA, this effect was attributed to flavonoids content [46]. Also, 
antimicrobial activity against Gram-negative bacteria was demonstrated [47-49].

In short, it appeared that when both $\mathrm{E}$ and Vit $\mathrm{C}$ were associated, Vit $C$ recovered its antioxidant activity independently the environmental conditions it was submitted, in this response, at least two mechanism could be involved; at low temperatures or short incubation times, it appeared that E, which was more stable, prevented oxidation of Vit $\mathrm{C}$, meanwhile at higher temperatures or longer incubation times the mechanism involved appeared to be the sum antioxidant effects. On the other hand the antimicrobial activity of the extract could explain the protection exerted by it on the oxidation process undergone by Vit C.

Finally, the aqueous extract of $L$. divaricata, with low NDGA content, could be used as antioxidant additive to preserve Vit $C$ from oxidation by air oxygen and as antimicrobial agent to prevent microbial contamination under different storage environmental conditions.

\section{Acknowledgements}

This work was supported by UBACYT Grant B116 from Buenos Aires, University. Roberto Davicino is a postdoctoral fellow of CONI-CET.

\section{REFERENCES}

[1] S. J. Padayatty, A. Katz, Y. Wang, E. P. Peter, O. Kwon, J.-H. Lee, S. Chen, C. Corpe, A. Dutta, S. K. Dutta, and M. Levine, "Vitamin C as an Antioxidant: Evaluation of Its Role in Disease Prevention Sebastian," Journal of the American College of Nutrition, Vol. 22, No. 1, 2003, pp. 18-35.

[2] V. A. Dickinson, G. Block and E. Russek-Cohen, "Supplement Use, Other Dietary and Demographic Variables, and Serum Vitamin C in NHANES II," Journal of the American College of Nutrition, Vol. 13, No. 16, 1994, pp. 22-32.

[3] D. B. Haytowitz, "Information from USDA's Nutrient Data Bank,” The Journal of Nutrition, Vol. 125, No. 7, 1995, pp. 1952-1955.

[4] B. Larisch, U. Groß and M. Pischetsrieder, "On the Reaction of L-Ascorbic Acid with Propylamine under Various Conditions: Quantification of the Main Products by HPLC/DAD," Zeitschrift fur Lebensmittel-Untersuchung Und-Forschung A, Vol. 206, No. 5, 1998, pp. 333-337. doi:10.1007/s002170050268

[5] E. Arena, B. Fallico and E. Maccarone, "Evaluation of Antioxidant Capacity of Blood Orange Juices as Influenced by Constituents, Concentration Process and Storage,” Food Chemistry, Vol. 74, No. 4, 2001, pp. 423-427. doi:10.1016/S0308-8146(01)00125-X

[6] H. S. Lee and G. A. Coates, "Vitamin C in Frozen, Fresh Squeezed, Unpasteurized, Polyethylene-Bottled Orange
Juice: A Storage Study,” Food Chemistry, Vol. 65, No. 2, 1999, pp. 165-168. doi:10.1016/S0308-8146(98)00180-0

[7] J. R. Johnson, R. J. Braddock and C. S. Chen, "Kinetics of Ascorbic Acid Loss and Nonenzymatic Browning in Orange Juice Serum: Experimental Rate Constants," Journal of Food Science, Vol. 60, No. 3, 1995, pp. 502505. doi:10.1111/j.1365-2621.1995.tb09812.x

[8] L. R. Gordon and M. C. Samaniego-Esguerra, "Effect of Soluble Solids and Temperature on Ascorbic Acid Degradation in Lemon Juice Stored in Glass Bottles,” Journal of Food Quality, Vol. 13, No. 5, 1990, pp. 361-374. doi:10.1111/j.1745-4557.1990.tb00032.x

[9] J. M. Smoot and S. Nagy, "Effects of Storage Temperature and Duration on Total Vitamin C Content of Canned Single-Strength Grapefruit Juice,” Journal of Agricultural and Food Chemistry, Vol. 28, No. 2, 1990, pp. 417-421. doi:10.1021/jf60228a050

[10] S. Naggy, "Vitamin C Contents of Citrus Fruits and Their Product: A Review,” Journal of Agricultural and Food Chemistry, Vol. 28, No. 1, 1980, pp. 8-18. doi:10.1021/jf60227a026

[11] V. O. Ajibola, O. A. Babatunde and S. Suleiman, "The Effect of Storage Method on the Vitamin C Content in Some Tropical Fruit Juices,” Trends in Applied Science Research, Vol. 4, No. 2, 2009, pp. 79-84. doi:10.3923/tasr.2009.79.84

[12] B. M. Laing, D. L. Schlueter and T. P. Labuza, "Degradation Kinetics of Ascorbic Acid at High Temperature and Water Activity,” Journal of Food Science, Vol. 43, No. 5, 1978, pp. 1440-1443. doi:10.1111/j.1365-2621.1978.tb02515.x

[13] A. M. Pedernera, T. G. Calderón, A. E. Rotelli, N. E. de la Rocha, S. D. Genaro and L. E. Pelzer, "Anti-Ulcerogenic and Anti-Inflammatory Activity of the Methanolic Extract of Larrea divaricata Cav. in Rat," Journal of Ethnopharmacology, Vol. 105, No. 3, 2006, pp. 415-420. doi:10.1016/j.jep.2005.11.016

[14] Anesini, C, Pérez, C. "Screening of plants used in Argentine folk medicine for antimicrobial activity". Journal of Ethnopharmacology 39, 1993, pp.119-128. doi:10.1016/0378-8741(93)90027-3

[15] Anesini, C, Genaro, A, Cremaschi, G, Sterin Borda, L, Cazaux, C, Borda E. Immunomodulatory Action of Larrea divaricata Cav. Fitoterapia 67, 1996, pp.329-333.

[16] K. J. Wang, C. R. Yang and Y. J. Zhang, "Phenolic Antioxidants from Chinese Toon (Fresh Young Leaves and Shoots of Toona sinensis,” Food Chemistry, Vol. 101, No. 1, 2007, pp. 365-371. doi:10.1016/j.foodchem.2006.01.044

[17] T. Osawa and M. Namiki, "A Novel Type of Antioxidant Isolated from Leaf Wax of Eucaliptus Leaves,” Agricultural Biological Chemistry, Vol. 45, No. 3, 1981, pp. 735740.

[18] D. P. Thompson, "Fungitoxic Activity of Essential Oil Component on Food Storage Fungi,” Mycologia, Vol. 81, No. 1, 1989, pp. 151-153. doi:10.2307/3759462 
[19] R. Filip, R. Davicino and C.Anesini, “Antifungal Activity of the Aqueous Extract of Ilex paraguariensis against Malassezia furfur,” Phytotheapy Research, Vol. 23, 2009, in press.

[20] C. Anesini, G. Ferraro, P. Lopéz and E. Borda, "Different Intracellular Signals Coupled to the Antiproliferative Action of Aqueous Extract from Larrea Divaricata Cav and Nor-Dihydroguaiaretic Acid on a Lymphoma Cell Line,” Phytomedicine, Vol. 81, No. 1, 2001, pp. 1-7. doi:10.1078/0944-7113-00006

[21] C. Anesini, S. Turner, E. Borda, G. Ferraro and J. Coussio, "Effect of Larrea Divaricata Cav Extract and Nordihy-Droguaiaretic Acid upon Peroxidase Secretion in Rat Sub-Mandibulary Glands," Pharmacology Research, Vol. 49, No. 5, 2004, pp. 441-448. doi:10.1016/j.phrs.2003.10.014

[22] B. Cvetkovic and M. Jokanovic, "Effect of Preservation Method and Storage Conditions on Ascorbic Acid Loss in Berberages,” APTEFF, Vol. 40, No. 1, 2009, pp. 1-7.

[23] I. Klimczak, M. Maecka, M. Szlachta, S. Gliszczynska and A. Wig, "Effect of Storage on the Content of Polyphenols, Vitamin C and the Antioxidant Activity of Orange Juices,” Journal of Food Composition and Analysis, Vol. 20, No. 3-4, 2007, pp. 313-322. doi:10.1016/j.jfca.2006.02.012

[24] V. Kabasakalis, D. Siopidou and E. Moshatou, “Ascorbic Acid Content of Commercial Fruit Juices and Its Rate of Loss upon Storage,” Food Chemistry, Vol. 70, No. 3, 2000, pp. 325-328. doi:10.1016/S0308-8146(00)00093-5

[25] O. Solomon, U. Svanberg and A. Sahlstrom, "Effect of Oxygen and Fluorescent Light on the Quality of Orange Juice during Storage at $8^{\circ} \mathrm{C}$," Food Chemistry, Vol. 53, No. 4, 1995, pp. 363-368. doi:10.1016/0308-8146(95)99828-N

[26] N. A. M. Eskin, "Biochemistry of Food Processing: Browning Reactions in Foods," Biochemistry of foods, Academic Press, London, 1990.

[27] K. Zerdin, M. L. Rooney and J. Vermue, “The Vitamin C Content of Orange Juice Packed in an Oxygen Scavenger Material," Food Chemistry, Vol. 82, No. 3, 2003, pp. 387-395. doi:10.1016/S0308-8146(02)00559-9

[28] D. H. Bullock, S. Singh and A. M. Pearson, "Our Industry Today: Stability of Vitamin C in Enriched Commercial Evaporated Milk 1,” Dairy Science, Vol. 51, No. 6, 1968, pp. 921-923. doi:10.3168/jds.S0022-0302(68)87106-1

[29] B. Larisch, U. Groß and M. Pischetsrieder, "On the ReacTion of L-Ascorbic Acid with Propylamine under Various Conditions: Quantification of the Main Products by HPLC/DAD,” Zeitschrift fur Lebensmittel-Untersuchung Und-Forschung A, Vol. 206, No. 5, 1998, pp. 333-337. doi:10.1007/s002170050268

[30] T. J. Mabry, D. R. Difeeo, M. Sakakibara, C. F. Bohnstedt and D. Seigler, "The Natural Products: Chemistry of Larrea.,” In: T. J. Mabry, J. H. Hunziker and D. R. Difeo, Eds., Creosote Bush Biology and Chemistry of Larrea in New World Desserts, Stroudsburg, Dowden, HutchinSon and Ross, Inc, Pennsylvania, 1977, p. 115.

[31] A. L. Bandoni, M. E. Mendiondo, V. D. Rondina and J. D. Coussio, "Survey of Argentine Medicinal Plants I: Folklore and Phytochemical Screening," Journal of Natural Products, Vol. 35, No. 1, 1971, pp. 69-80.

[32] B. Timmerman, A. valesi and T. Mabry, "Flavonoids from Larrea Nitida, Divaricata and Cuneifolia," Revista Latino -Americana de Química, Vol. 10, No. 3, 1979, pp. 81-83.

[33] I. Erlund, "Review of the Flavonoids Quercetin, Hesperedin and Naringenin, Dietary Sources, Bioactivities and Epidemiology," Nutrition Research, Vol. 24, No. 10, 2004, pp. 851-874. doi:10.1016/j.nutres.2004.07.005

[34] R. Schreck, K. Albermenn and P. A. Bauerle, "Nuclear Factor KB: An Oxidative Stress-Responsive Transcription Factor of Eukaryotic Cells (A Review)," Free Radical Research Communications, Vol. 17, No. 4, 1992, pp. 221-237. doi:10.3109/10715769209079515

[35] S. Franchi-Micheli, S. Luzzi, M. Ciufti and L. Zilletti, "The Effects of Lipoxygenase Inhibitors and Leuk Otriene Antagonist on Anaphylaxis,” Agent Actions, Vol. 18, No. 1-2, 1986, pp. 242-244. doi:10.1007/BF01988031

[36] M. Sulin, "Letter to the Editor: "Antioxidant Therapy, Larrea and Livestock,” Age, Vol. 12, No. 1, 1989, p. 37.

[37] W. Coy and O. Gisvold, "A Phytochemical Investigation of Larrea divaricata Cav," Journal of the American Pharmacists Association, Vol. 34, No. 3, 1994, pp. 78-81.

[38] W. R. Obermeyer, S. M. Musser, J. M. Betz, R. E. Casey, A. E. Pohland and S.W. Page, "Chemical Studies of PhyToestrogens and Related Compounds in Dietary SuppleMents: Flax and Chaparral," Proceedings of the Society for Experimental Biology and Medicine, Vol. 208, No. 1, 1995, pp. 6-12.

[39] S. C. Sahu, D. I. Ruggles and M. W. O’Donnell, "Prooxidant Activity and Toxicity of Nordihydroguaiaretic Acid in Clone-9 Rat Hepatocyte Cultures,” Food and Chemical Toxicology, Vol. 44, No. 10, 2006, pp. 1751-1757. doi:10.1016/j.fct.2006.05.016

[40] J. D. Lambert, D. Zhao, R. O. Meyers, R. K. Kuester, B. Timmermann and R. Dorr, "Nordihydroguaiaretic Acid: Hepatotoxicity and Detoxification in the Mouse,” Toxicon, Vol. 40, No. 12, 2002, pp. 1701-1708. doi:10.1016/S0041-0101(02)00203-9

[41] L. Frasier and J. P. Kehrer, "Effect of Indomethacin, Aspirin, Nordihydroguaiaretic Acid, and Piperonyl Butoxide on Cyclophosphamide Induced Bladder Damage," Drug Chemical Toxicology, Vol. 16, No. 2, 1993, pp. 117-133. doi:10.3109/01480549309031992

[42] Z. Y. Wang, R. Agarwal, Z. C. Zbou and D. R. Bickers, "Antimutagenic and Antitumorigenic Activities of Nordihy-Droguaiaretic Acid,” Mutation Research, Vol. 261, No. 3, 1991, pp. 155-162.

[43] E. Madrigal-Bujaidar, S. Diaz Barriga, M. Cassani, P. Marquez and P. Revuelta, "In vivo and in vitro AntiGenotoxic Effect of Nordihydroguaiaretic Acid against Sces Induced by Methyl Methanesulfonate," Mutation Research, Vol. 419, No. 1-3, 1998, pp. 163-168. 
[44] Y. H. Siddique, T. Beg and M. Afzal, "Protective Effect of Nordihydroguaiaretic Acid (NDGA) against Norgestrel Induced Genotoxic Damage,” Toxicology in Vitro, Vol. 20, No. 2, 2006, pp. 227-233. doi:10.1016/j.tiv.2005.06.027

[45] C. Pérez and C. Anesini, "Antibacterial Activity of Alimentary Plants against Staphyloccocus Aureus Growth," American Journal of Chinese Medicine, Vol. 22, No. 2, 1994, pp. 169-174. doi:10.1142/S0192415X94000206

[46] P. W. Stege, R. C. Davicino, A. E. Vega, Y. A. Casali, S. Correa and B. Micalizzi, "Antimicrobial Activity of Aqueous Extracts of Larrea Divaricata Cav (Jarilla) against Helicobacter Pylori,” Phytomedicine, Vol. 13, No. 9-10, 2006, pp. 724-727. doi:10.1016/j.phymed.2005.06.008
[47] M. E. Arias, J. D. Gómez, M. A. Vattuone and M. I. Isla, "Antibacterial Activity of Ethanolic and Aqueous Extract of Acacia Aroma Gill Ex Hook Et,” Life Science, Vol. 75, No. 2, 2004, pp. 191-202. doi:10.1016/j.lfs.2003.12.007

[48] I. C. Zampini, M. Vattuone and M. I. Isla, “Antibacterial Activity against Antibioticresistant Gramnegative Human Pathogenic Bacteria of Hydroxychalcone Isolated from Zuccagnia Punctata Cav,” Journal of Ethnopharmacology, Vol. 102, No. 3, 2005, pp. 450-456. doi:10.1016/j.jep.2005.07.005

[49] I. C. Zampini, N. Cudmani, M. I. Isla, "Antimicrobial Activity of Argentine Medicinal Plants on AntibioticResistant Bacteria," Acta Bioquímica Clínica Latinoamerican, Vol. 41, No. 3, 2007, pp. 385-393. 